\title{
El marco regulatorio de las patentes en la reestructuración de los sistemas de innovación y la nueva migración calificada
}

\author{
The regulatory framework of patents within the restructuring of \\ innovation systems and the new skilled migration phenomenon
}

Julián Pinazo-Dallenbach*
Raúl Delgado Wise ${ }^{\star \star}$
ISSN IMPRESO 1870-7599 | ISSN RED CÓMPUTO 2448-7783 | 45-69

RECIBIDO: 20/04/2018 | ACEPTADO: 02/05/2018

\begin{abstract}
Resumen. Asistimos a una fase crítica del desarrollo capitalista donde la propiedad intelectual y las patentes se han convertido en un aspecto consustancial a la lógica de reestructuración neoliberal promovida por las grandes corporaciones multinacionales y los gobiernos imperialistas encabezados por Estados Unidos. Ello ha dado lugar a una expansión, concentración y apropiación privada sin precedentes de los productos del general intellect, que lejos de propiciar una ruta progresista de desarrollo de las fuerzas productivas, ha desencadenado dinámicas regresivas de degradación social y ambiental. A partir de esas consideraciones, nos proponemos lo siguiente: a) contribuir a desentrañar la forma como se han reestructurado los sistemas de innovación en la actualidad, tomando como referente el caso emblemático de Silicon Valley; b) analizar, desde un mirador jurídico-crítico, la nueva normativa e institucionalidad internacional en materia de patentamiento; y c) esclarecer el significado que, en este contexto, adquiere la nueva migración calificada proveniente de países periféricos y emergentes.
\end{abstract}

Palabras clave: propiedad intelectual, patentes, reestructuración de los sistemas de innovación, derecho internacional, migración altamente calificada.

\begin{abstract}
We are experiencing a critical phase of capitalist development in which intellectual property and patents have become an intrinsic aspect of the neoliberal restructuring logic promoted by the large multinational corporations and imperial governments, led by the United States. This has led to an unprecedented expansion, concentration and private appropriation of the products of the general intellect, which rather than foster a progressive path to development of the forces of production, has triggered regressive dynamics of social and environmental degradation. With these considerations in mind, we propose: a) to contribute to an understanding of the way in which current systems of innovation have been restructured, taking into account the emblematic case of Silicon Valley; b) analyse, from a critical-legal perspective, the new regulations and international institutionalism with regard to patenting; and c) clarify the significance - in this context - of the new skilled migration coming from peripheral and emerging countries.
\end{abstract}

Keywords: intellectual property, patents, restructuring of innovation systems, international law, highly skilled migration.

\footnotetext{
* Español. Doctorante en Estudios del Desarrollo, Universidad Autónoma de Zacatecas, México. Correo-e: julianpinazo@hotmail.com

** Mexicano. Director de la Unidad Académica en Estudios del Desarrollo, Universidad Autónoma de Zacatecas, México. Correo-e: rdwise@uaz.edu.mx
} 


\section{Introducción}

El capitalismo contemporáneo se caracteriza por una excesiva concentración y centralización del capital en un puñado de grandes corporaciones multinacionales, a grado tal que Samir Amin (2015) se refiere a él como la era de los monopolios generalizados. Al respecto, «es preciso observar que, mediante megafusiones y alianzas estratégicas, dicha fracción del capital ha alcanzado niveles de concentración y centralización hasta hace relativamente poco inimaginables» (Delgado, 2017:48). Tómese en consideración que «las compañías más grandes del mundo (aquellas con más de mil millones de dólares estadounidenses en ventas anuales) (...) representan aproximadamente 60 por ciento de los ingresos, 65 por ciento del mercado de capitalización y 75 por ciento de las ganancias (mundiales)» (McKinsey Global Institute, 2015:21).

Esta omnipresencia de la gran corporación multinacional es producto y resultado del profundo proceso de reestructuración emprendido por el capital monopolista bajo la égida neoliberal, a través de tres factores: a) el recurso a la financiarización; b) el desplazamiento de parte de los procesos productivos, comerciales y de servicios hacia los países periféricos en busca de fuerza de trabajo barata; c) el saqueo de recursos naturales y el acaparamiento de tierras (Delgado, 2017).

Es importante subrayar que dicha serie de transformaciones no sería imaginable siquiera sin el avance de las tecnociencias y, en específico, de las tecnologías de la información y de las telecomunicaciones (TICs). Gracias a esos avances "el conocimiento y el cambio tecnológico (son colocados) en el centro de los procesos de valorización del capital» (Míguez, 2013:27). En este sentido, resulta innegable la relevancia del conocimiento en las dinámicas de acumulación de capital en la actualidad, incluso algunos teóricos añaden al capitalismo contemporáneo el adjetivo de cognitivo, frente a otras expresiones como sociedad del conocimiento o sociedad de la información. De manera que se busca enfatizar que nos encontramos ante una fase del desarrollo capitalista en la que, como argumenta Ramírez, «las nuevas formas de explotación económica (...) se sustentan en la expropiación del conocimiento» (2017:103). Empero, ello no significa que el móvil del sistema sea el conocimiento, sino más bien que éste se convierte en un poderoso medio para acrecentar las ganancias y más específicamente las ganancias extraordinarias del capital monopolista. En tal contexto, la figura de la propiedad intelectual, existente desde hace siglos, emerge con más fuerza que nunca, pues 
permite objetivar el conocimiento, cercándolo como si fuese un derecho privativo. En opinión de Bolívar Echeverría, «la primera tarea que cumple la economía capitalista es la de reproducir la condición de existencia de su propia forma: construir y reconstruir incesantemente una escasez artificial, justo a partir de las posibilidades renovadas de la abundancia» (2011:85). La creación de la figura de la propiedad intelectual mediante las patentes permite la limitación, la parcelación del conocimiento, su mercantilización y su escasez artificial.

Así, el capital monopolista consigue obtener ganancias extraordinarias, es decir, ganancias superiores a la media, razón de ser de su existencia; no obstante, debe «mantener ventajas duraderas sobre otros posibles participantes en la rama o ramas particulares en las que opera. Tales ventajas pueden ser naturales o artificiales» (Delgado, 2017:52). Es en este punto donde la innovación adquiere un papel fundamental en la búsqueda de esas ventajas y su mantenimiento, el capital monopolista acelera la innovación y el progreso/cambio tecnológico, pero siempre teniendo en mente el valor de cambio, no el valor de uso. ${ }^{1}$ La tecnología desarrollada permite conservar dichas ganancias extraordinarias por medio del aumento de productividad, derivado de su aplicación o por medio de la acumulación de títulos de propiedad monopólica (las patentes) utilizados como activos intangibles o para el impedimento legal de su utilización por otras personas. En efecto:

La tentación de obstruir la difusión del progreso tecnológico está siempre allí, en el productor capitalista que obtiene una ganancia extraordinaria por el uso exclusivo que de él realiza. Pero esta tentación no puede durar mucho tiempo siendo una tentación, tiene que convertirse en un comportamiento aceptado, normal e institucional, como ha sido el caso en la vida real del capitalismo histórico durante los últimos cien años (Echeverría, 2011:682).

Con fundamento en estas grandes consideraciones, un aspecto central de la metamorfosis, experimentada por el capital monopolista en el presente, es la reestructuración que experimentan los sistemas de innovación, donde la trascendencia del trabajo científico-tecnológico y las modalidades de su organización y su apropiación por la gran corporación multinacional adquieren una dimensión estratégica.

${ }^{1}$ La importancia de esto reside en que los beneficios serán para el capital monopolista, no para la sociedad. Esta instrumentalización de la ciencia por parte de las corporaciones se encuentra en la base de muchas crisis humanitarias tales como pandemias o hambrunas. 
Los mecanismos jurídicos para la apropiación del trabajo científico-tecnológico, con la patente como pieza nodal de la reestructuración de los sistemas de innovación, devienen en una pieza básica para la apropiación de ganancias extraordinarias y la regulación de los mercados mundiales por las grandes corporaciones multinacionales en mancuerna con el Estado imperial. En el contexto de la globalización neoliberal «las empresas necesitan ahora nuevas reglas internacionales para garantizar su actividad. Entre ellas, la regulación internacional de los derechos de propiedad intelectual» (Vidaurreta, 2013:3). De ahí que el derecho internacional funja como una pieza medular del control y apropiación del trabajo científico-tecnológico y, por ende, de la reestructuración de los sistemas de innovación, a través de una serie de convenios internacionales regulatorios de la propiedad intelectual y el comercio.

En este complejo entramado, la fuerza de trabajo calificada migrante - sobre todo aquella proveniente de países periféricos - se convierte en una mercancía esencial para cubrir la creciente necesidad de científicos y tecnólogos por parte de los países imperialistas y sus corporaciones. Las teorías explicativas de la migración calificada, como el brain drain, brain gain, brain waste y brain abuse, y la que está más en boga hoy, brain circulation, son teorías descontextualizadas, superficiales y esencialmente descriptivas, ${ }^{2}$ en tanto que no explican las causas e implicaciones de la migración calificada (Delgado, 2015).

El propósito del presente artículo es contribuir a desentrañar ese fenómeno, poniendo especial énfasis en el marco jurídico del sistema internacional de patentes, así como en las características de la nueva migración calificada en relación con la reestructuración de los sistemas de innovación. El trabajo se organiza en tres secciones. En la primera se abordan las nuevas formas de apropiación del trabajo científico-tecnológico — del general intellect ${ }^{3}$ utilizando el concepto acuñado por Marxen el marco de la reestructuración de los sistemas de innovación que caracteriza al

\footnotetext{
${ }^{2}$ Cada una de éstas pone énfasis en el país emisor (perjudicado, por eso es brain drain), país receptor (beneficiado, por eso es brain gain) o en el propio migrante (brain waste y brain abuse). El brain circulation, por su parte, propone un win-win-win, al considerar que tanto el país de origen como el de destino, y también el propio migrante, ganan con la migración, sacan provecho de ella.

${ }^{3}$ Según Marx, el general intellect se erige con el advenimiento del capitalismo en una fuerza de producción vital. El concepto alude a una combinación de experiencia tecnológica e intelecto social, o conocimiento social general, que, con el advenimiento de la gran industria, adquiere una importancia creciente en la organización social. El pasaje del general intellect en la sección "Fragmentos» de Grundrisse, muestra que si bien el desarrollo de la maquinaria condujo a la opresión de los trabajadores bajo el capitalismo, también ofrece una perspectiva para la liberación futura.
} 
capitalismo contemporáneo, tomando como referente el caso emblemático de Silicon Valley. En la segunda se efectúa un análisis jurídico-crítico de la nueva normativa e institucionalidad internacional en materia de propiedad intelectual y patentes. Por último, en la tercera se examina la nueva migración altamente calificada proveniente de los países periféricos que se desencadena en este contexto.

\section{Las nuevas formas de apropiación del general intellect y la reestructuración de los sistemas de innovación}

Las teorías de la innovación comienzan considerando que ésta proviene de un empresario individual (teorías schumpeterianas), para luego concebirla como un proceso colectivo en el que interaccionan diversas instituciones y actores que integran un Sistema de Innovación (Niosi et al., 1993), compuesto por «all important, economic, social, political, organizational, institutional, and other factors that influence the development, diffusion, and use of innovations» (Edquist, 1997:14). A diferencia del trabajo inmediato que realiza el obrero en la fábrica, el trabajo científico-tecnológico o general intellect se caracteriza por su creatividad y reclama, por tanto, formas de organización muy diferentes y contrastantes a las que imperan en la fábrica y que, con el avance de la ciencia, tienden a revolucionarizarse de modo permanente. De manera que el Sistema de Innovación «está simplemente en el centro del pensamiento moderno sobre la innovación y su relación con el crecimiento económico, la competitividad y el empleo» (Edquist, 2001:4).

Se han planteado diversos modelos que describen lo que en la literatura neo-schumpeteriana se conoce como Sistema Nacional de Innovación: el modelo lineal, ${ }^{4}$ el modelo interactivo, ${ }^{5}$ el triángulo de Sábato ${ }^{6}$ y la triple hélice ${ }^{7}$ (Castillo,

${ }^{4}$ En el modelo lineal se genera conocimiento en la Universidad o en los laboratorios científicos bajo las normas de la ciencia. La transmisión de ese conocimiento se realiza a través de las publicaciones científicas (Castillo, Lavín y Pedraza, 2014).

${ }^{5}$ En dicho modelo predomina «la aplicabilidad y utilidad social de la investigación» (Castillo, Lavín y Pedraza, 2014:440). Estos mismos autores indican que aquí adquiere relevancia la empresa respecto al modelo lineal.

${ }^{6}$ Este modelo fue el utilizado durante la época de Industrialización por Sustitución de Importaciones. La característica principal es que el Estado es el que guía el proceso de innovación mediante la promulgación e implementación de normativa y política pública.

${ }^{7}$ La diferencia fundamental entre la triple hélice y el triángulo de Sábato es que en la primera la ciencia pasa de ser impulsada por el Estado a estar dirigida por el mercado (Záyago, 2013). Principales autores de este modelo: Etzkowitz y Leydesdorff (Castillo, Lavín y Pedraza, 2014). 
Lavín y Pedraza, 2014). No obstante, ninguno de ellos resulta adecuado para captar la dinámica, agentes e instituciones participantes y, ante todo, las formas de apropiación del general intellect propias de los complejos sistemas - o ecosistemas - de innovación que distinguen al capitalismo contemporáneo. Al respecto, Raúl Delgado Wise (2015) y Delgado Wise y Mónica Chávez (2016) mencionan que bajo la égida neoliberal se ha producido una profunda reestructuración de los sistemas de innovación caracterizada por distintos aspectos.

En primer lugar, la internacionalización y fragmentación de las actividades de investigación y desarrollo (I+D), las cuales han dejado de llevarse a cabo al interior de las empresas (en esquemas a «puertas cerradas»). Se trata, principalmente, de modalidades «colectivas»: peer-to-peer, share economy, commons economy y crowdsourcing economy, que configuran modalidades de innovación abierta (open innovation), que implican una apertura y redistribución espacial de funciones corporativas intensivas en conocimiento con la creciente participación de socios externos: start-ups, proveedores, clientes, subcontratistas, universidades y centros de investigación. La nueva forma de organizar el general intellect ha propiciado la permanente configuración y reconfiguración de redes de innovación. Ello significa que los trabajadores calificados, principalmente en áreas relacionadas con la innovación — ciencias, tecnología, ingeniería y matemáticas (CTIM)—, tienen un objetivo que cumplir en las dinámicas de innovación; no obstante, éste se inscribe en un proceso de investigación mucho más amplio, motivo por el que en muchas ocasiones se desconoce cuál será el producto final (Foladori, 2014).

La creación de ciudades científicas en segundo término. En ellas se concentran gran parte de los procesos de I+D. Se trata de complejos ecosistemas que operan como aceleradores del conocimiento y la creatividad científico-tecnológica. El caso paradigmático es Silicon Valley, en Estados Unidos, que opera como núcleo del proceso de reestructuración referido con un agregado: en torno a Silicon Valley se ha creado un tejido de ciudades científicas en países periféricos o emergentes, como Bangalore en la India o Mar de Plata en Argentina. El ecosistema de Silicon Valley es la punta de lanza de las nuevas formas de control, aceleración y apropiación del trabajo científico y tecnológico. Se ha erigido en el principal polo de innovación mundial a través de su desbordante generación de patentes, en tanto formas de apropiación de los productos del general intellect.

En tercer lugar, la expansión en el horizonte norte-sur de la fuerza de trabajo en áreas CTIM y el creciente reclutamiento de fuerza de trabajo altamente calificada proveniente, en específico, de países periféricos o emergentes por vía 
outsourcing y offshoring. En ese sentido es pertinente advertir que la migración altamente calificada - a la que haremos referencia en el último apartado de este trabajo- desempeña un papel cada vez más relevante en los procesos de innovación, lo que genera una paradójica y contradictoria dependencia del norte o centro respecto del sur o periferia del sistema mundo capitalista.

Por último, una cuarta y fundamental característica se refiere a las nuevas formas de control de las agendas de investigación y de apropiación de los productos del trabajo científico-tecnológico. Es indispensable subrayar al respecto que la gran corporación multinacional o el capital monopolista en mancuerna con el Estado imperial son quienes hegemonizan este proceso a través de lo que se conoce como inversión estratégica (strategic investment). ${ }^{8}$ Dicho control se desarrolla en varios planos, desde la diversificación de capital de riesgo, la presencia de buscadores de talento (head hunters) por parte de las grandes corporaciones, el establecimiento de contratos diversos de subcontratación o asociación con los inventores independientes (startup), hasta el patentamiento en el marco de la normativa internacional establecida por la Organización Mundial de la Propiedad Intelectual (OMPI) en mancuerna con la Organización Mundial del Comercio (OMC). Es necesario enfatizar que esta diversidad de mecanismos de control y apropiación de los productos del general intellect recaen en equipos especializados de abogados al servicio del capital corporativo. En ese marco, la ciencia se convierte en un producto, una mercancía. La patente, como figura paradigmática de la propiedad intelectual, opera como un título que otorga poder y derechos privativos a la corporación que la posee, independientemente de que sea aplicada o no para la comercialización de un producto, hecho que da lugar a lo que Guillermo Foladori (2014) denomina ciencia ficticia. Así, la innovación contenida en el título de la patente podrá transformarse en un producto real y venderse en el mercado, o podrá acumularse, junto con otras patentes, aumentando el poder monopólico de la corporación para acumular riqueza, regular mercados o ser utilizada como objeto de especulación o instrumento para demandas ante los tribunales (es el caso de las llamadas patentes troll). De esta forma, las corporaciones multinacionales son las que establecen las agendas de investigación y se apropian

\footnotetext{
${ }^{8}$ Se trata de inversiones en otras empresas, generalmente de alta tecnología (startups), que están comenzando y necesitan inyecciones importantes de capital, pero todavía no pueden o tienen complicado concurrir en el mercado de capitales. Las empresas que realizan el strategic investment buscan rentabilizar la inversión a través del control o la obtención de información sobre determinados productos o tecnologías de la empresa en la que inyectan el capital (Graffagnini, 2009).
} 
de las innovaciones que de éstas se derivan, al controlar la información sobre determinados productos o tecnologías, secretos o estrategias de mercado, incluso reducir riesgos y optimizar ganancias (Graffagnini, 2009).

\section{El marco actual de propiedad intelectual y patentes en el sistema capitalista contemporáneo: un análisis jurídico crítico}

\section{¿En qué consiste la propiedad intelectual?}

La propiedad intelectual es una categoría de propiedad que abarca «las creaciones de la mente» (OMPI). Comprende, por una parte, la llamada propiedad industrial (patentes, modelos de utilidad, marcas, diseños industriales, secretos comerciales, obtenciones vegetales e indicaciones geográficas) y, por otra, el derecho de autor y derechos conexos. La Organización Mundial de la Propiedad Intelectual define la patente como

un derecho exclusivo que se concede sobre una invención. En términos generales, una patente faculta a su titular a decidir si la invención puede ser utilizada por terceros y, en ese caso, de qué forma. Como contrapartida de ese derecho, en el documento de patente publicado, el titular de la patente pone a disposición del público la información técnica relativa a la invención (OMPI).

Como veremos más adelante, no toda invención puede ser patentada, sino que es necesario que cumpla una serie de requisitos fijados normativamente. ${ }^{9}$ Antes de estudiar la normativa, hablemos de tres actores fundamentales en el marco internacional actual de las patentes: el Estado, los organismos internacionales (concretamente: la OMPI y la OMC) y las corporaciones multinacionales.

${ }^{9}$ Para poder patentar una invención, los requisitos generales son novedad, aplicabilidad industrial, no obviedad. 


\section{El papel del Estado, los organismos internacionales \\ y las corporaciones multinacionales tras el Consenso de Washington}

Con la instauración del neoliberalismo, por ejemplo el llamado Consenso de Washington, se produce - como apuntamos al principio - una profunda reestructuración del capital monopolista, comandada por los Estados imperiales bajo la batuta de Estados Unidos. Este fenómeno guarda relación con la creación de una serie de organismos internacionales, cuyo poder ha sido tal que derivó en un pluralismo jurídico ${ }^{10}$ de alcance global que «no sólo es importante para la operación de las redes económicas globales, sino que les es esencialmente constitutivo» (Hernández, 2014:132). Esto ha implicado una progresiva pérdida de soberanía del Estado, sujeto primario del derecho internacional, frente a los organismos internacionales y el poder de las grandes corporaciones multinacionales, sobre todo en el caso de los países periféricos (López, 2014).

Las organizaciones internacionales a través de las cuales se apuntala el orden (o desorden) neoliberal imperante son, además de las llamadas instituciones de Bretton Woods, el Banco Mundial (BM) y el Fondo Monetario Internacional (FMI), la OMC y - gracias a la creciente importancia de las patentes y la propiedad intelectual en el imperialismo contemporáneo—-la OMPI (Hernández, 2014; Vargas, 2012).

Conforme a nuestros fines analíticos, de los cuatro organismos internacionales referidos nos interesan particularmente los dos últimos: la OMPI, en tanto agencia de las Naciones Unidas especializada en la innovación y el establecimiento de un régimen de propiedad intelectual; y la OMC, por su estrecha vinculación con aquella mediante la inclusión en el convenio constitutivo del Acuerdo sobre los Aspectos de los Derechos de Propiedad Intelectual relacionados con el Comercio (Acuerdo ADPIC). Es indispensable destacar que la OMPI y la OMC suscribieron en 1995 un convenio de mutuo apoyo, con el propósito de facilitar la aplicación del Acuerdo ADPIC; con ello evidenciaron la instrumentalización de la OMPI para los fines de expansión y dominio de las grandes corporaciones multinacionales.

\footnotetext{
${ }^{10}$ De acuerdo con Liliana López (2014), la discusión acerca del pluralismo jurídico no es nueva, pues sus orígenes se remontan a la década de los 1930. La argumentación gira en torno a la pérdida por parte del Estado del monopolio normativo. A efectos de la presente investigación, es de interés esta pérdida en el contexto de la globalización y del capitalismo contemporáneo.
} 
La OMPI es una institución internacional creada en $1967,,^{11}$ con el mandato expreso de «estimular la actividad creadora (y) promover en todo el mundo la protección de la propiedad intelectual» (preámbulo del Convenio OMPI). En la actualidad cuenta con 192 Estados miembro. Su sede central se ubica en Ginebra, Suiza, y dispone de oficinas de enlace en Río de Janeiro, Brasil, Singapur, Singapur, Tokio, Japón, y una oficina en la sede central de las Naciones Unidas en Nueva York, Estados Unidos.

Por su parte, la OMC — creada el primero de enero de 1995 con la entrada en vigor del Acuerdo de Marrakech - es una institución que reemplaza al General Agreement on Tariffs and Trade (GATT). Más que un simple tratado en materia comercial, la OMC se erige como el organismo encargado de organizar y normativizar el comercio internacional, no sólo en el comercio de mercancías (como era el caso del GATT), sino también en el ámbito de los servicios y la propiedad intelectual.

La entrada en vigor del Acuerdo de Marrakech entraña un salto importante en la regulación de la propiedad intelectual, ya que pasa a formar parte del marco normativo del comercio internacional al incluírsele en el Anexo 1C del Acuerdo ADPIC. Tal acuerdo conlleva el ingreso de la propiedad intelectual en el sistema multilateral de comercio de la OMC, y supone asimismo que todos los miembros de la organización cumplan con lo establecido. Ello obliga a una adecuación de las normativas internas en relación con los mínimos fijados en este acuerdo y, además, a la disposición de someterse al sistema de resolución de controversias de la Organización. En opinión de Christian Schmitz, «la verdadera globalización de la propiedad intelectual se produce con la celebración del Acuerdo sobre los ADPIC en el año 1994» (2013:86).

La instauración de la OMC ha implicado una profunda pérdida de autonomía y de los márgenes de maniobra de la OMPI en materia de propiedad intelectual (Rodríguez, 2008). En efecto, la introducción de la propiedad intelectual en el Acuerdo de Marrakech expresa la importancia asignada por las principales potencias capitalistas — encabezadas por Estados Unidos - a contar con un sistema de patentes que coadyuvara a la expansión y regulación del comercio internacional de conformidad con los intereses hegemónicos de las grandes corporaciones multinacionales. Como lo destaca Francesca Rodríguez (2008), previo al

${ }^{11}$ El instrumento fundacional es el Convenio que establece la Organización Mundial de la Propiedad Intelectual, firmado en Estocolmo (Suecia). Fue enmendado en septiembre de 1979. 
Acuerdo de Marrakech, la OMPI resultaba un lastre para los intereses de los principales países imperialistas, en virtud de su lentitud para la toma de decisiones y el creciente peso que en ella tenían los países periféricos. Con la introducción del Anexo 1C en el Acuerdo de Marrakech y la posterior firma del convenio de mutuo apoyo entre la OMPI y la OMC para facilitar la aplicación del Acuerdo ADPIC, los países centrales (principalmente Estados Unidos) y sus corporaciones consiguieron establecer, por la vía jurídica, barreras a la entrada y mecanismos para reforzar su predominio y control sobre las patentes y la propiedad intelectual.

Desde el punto de vista del derecho internacional, la creación de la OMC y la introducción de la propiedad intelectual en el sistema de comercio multilateral representan un hito, en virtud de que esta organización detenta el poder de crear normativa aplicable a los Estados miembro y, además, dispone de mecanismos para su observancia e incluso para la solución de controversias. De esa manera, el papel del Estado como motor de desarrollo, se ve severamente constreñido, en particular dentro del ámbito de los países periféricos, donde parte del tradicional monopolio normativo del Estado es transferido a los organismos internacionales a través del carácter vinculante de los instrumentos jurídicos impulsados por éstos (Hernández, 2014). Se configura entonces un poder político supranacional, donde organismos como la OMC y la OMPI «gozan a menudo de poderes de decisión que les permiten configurar las políticas públicas, promocionar con fuerza medidas legislativas, impulsar o desalentar reformas sociales e influenciar la acción gubernamental en áreas esenciales» (Amin, 2013:86).

\section{Principales textos normativos en materia de propiedad industrial y patentes}

El primer gran tratado internacional en materia de propiedad industrial es el Convenio de París para la Protección de la Propiedad Industrial de 1883. Este texto normativo, que aún continúa en vigor, se redactó en un contexto muy peculiar. La figura de la propiedad industrial ya existía en algunos países, pero su protección era desigual, puesto que cada uno tenía su propia normativa. Según Schmitz (2013), había mucha heterogeneidad y el aspecto central de las leyes nacionales era la territorialidad, por lo que su interés primordial era proteger las creaciones nacionales: los inventores veían sus innovaciones desprotegidas en el extranjero, donde solían ser con frecuencia utilizadas por resultar más económicas 
que las nacionales. Las presiones ejercidas por los grandes inventores llevaron finalmente a algunos países industrializados a reunirse y suscribir el Convenio de París. Las principales novedades fueron, en primer lugar, la constitución de una Unión de países para la protección de la propiedad industrial (artículo 1-1 del Convenio), la introducción del principio de trato nacional, esto es, proteger las invenciones de los nacionales de otros países de la Unión de la misma forma que a los nacionales propios (artículo 2) y el derecho de prioridad, lo que suponía que el depósito de una solicitud de patente en un país tenía preeminencia durante 12 meses antes de depositar la solicitud en otros de la Unión (artículo 4). Schmitz considera que este convenio es «el primero en su materia y constituye la base del sistema internacional de protección de derechos industriales» (2013:72).

Otro tratado internacional esencial en el sistema internacional de patentes es el Tratado de Cooperación en materia de Patentes (TCP), adoptado en 1970, el cual fue enmendado en 1979 y modificado en 1984 y 2001. El reglamento también se adoptó en 1970 y se cambió en múltiples ocasiones sucesivas. Dichos textos normativos configuran un sistema de solicitud internacional de patentes y un sistema de protección a escala mundial.

El procedimiento establecido a través del TCP consta de cuatro fases. En primer lugar, la presentación de la solicitud en la Oficina de un Estado contratante («oficina receptora», art. 10 del tratado) de donde será enviada a la Oficina Internacional (art. 12-1). En segundo lugar, se realizará una búsqueda internacional para descubrir el estado de la técnica pertinente (art. 15-2). En tercer término, la publicación internacional de una solicitud supondrá que la solicitud surtirá efectos en el Estado del que se ha solicitado protección (art. 29-1). Finalmente, el tratado establece varios órganos administrativos: la Asamblea (art. 53), el Comité Ejecutivo (art. 54), la Oficina Internacional (art. 55) y el Comité de Cooperación Técnica (art. 56). Del reglamento destaca el establecimiento de un plazo de hasta 30 meses del derecho de prioridad. La mera presentación de la solicitud bloquea ya otras posibles solicitudes de patente durante dos años y medio (véase figura 1). Este tratado cuenta actualmente con 152 Estados contratantes. 


\section{FIGURA 1}

Tratado de Cooperación en materia de Patentes, OMPI

\section{Meses a contar desde la fecha de prioridad:}

Solicitud presentada ante una oficina de patentes (fecha de prioridad)

Solicitud internacional presentada ante la oficina receptora del PCT

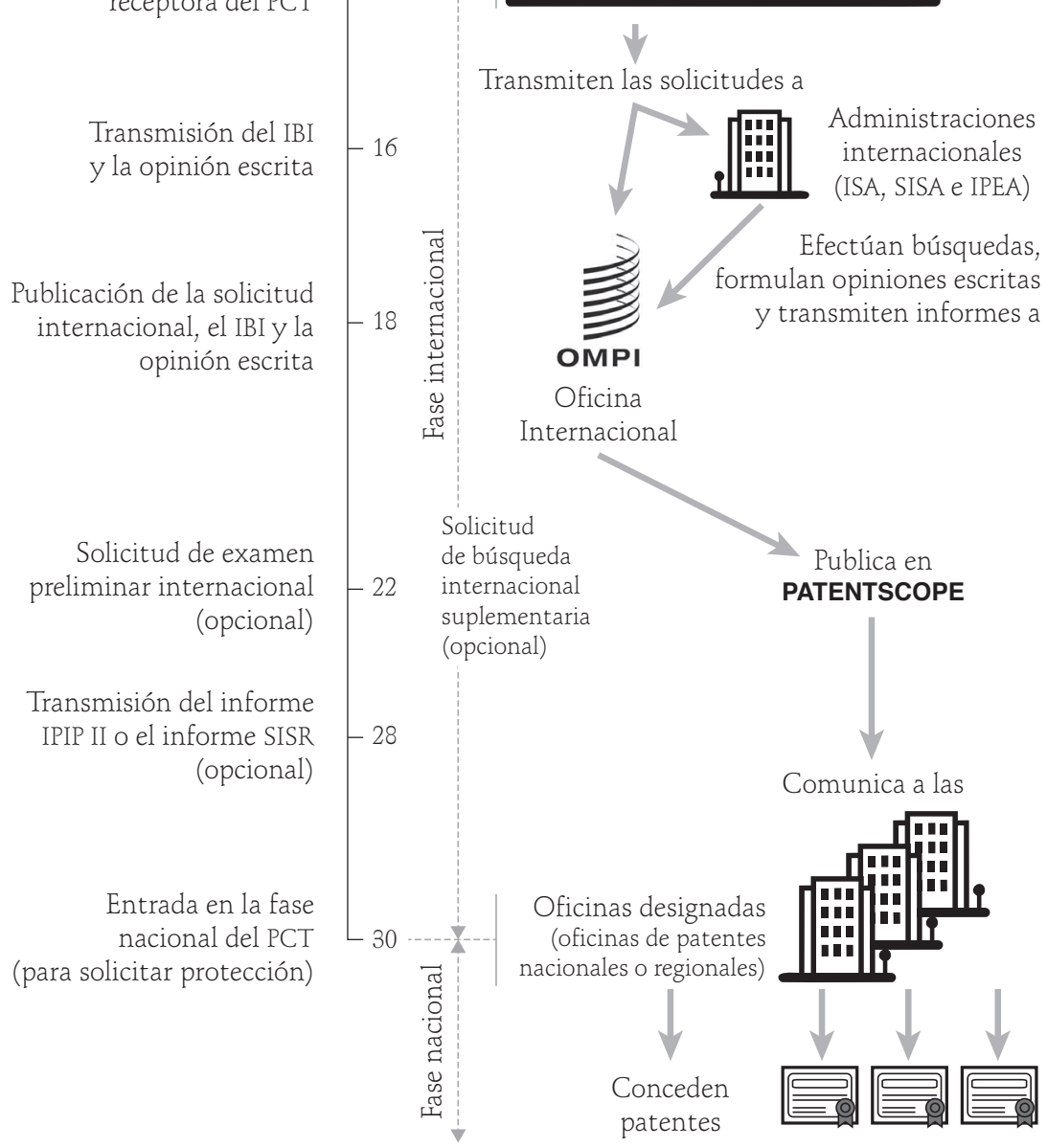

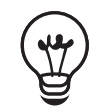

Invenciones

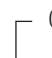

\section{Solicitudes} internacionales

Presentadas ante
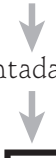

Oficinas receptoras

(oficinas de patentes nacionales o regionales o la Oficina Internacional)

Fuente: imagen adaptada de la OMPI, 2017. 
Otro tratado relacionado con las patentes es el Tratado sobre el Derecho de Patentes, adoptado en el año 2000, y su reglamento puesto en vigor el 1 de enero de 2006. Este tratado internacional versa sobre las patentes de invención y las patentes de adición, tanto nacionales como regionales. Es un tratado mucho más técnico, en el sentido de que explica los requisitos de las solicitudes de registro de patentes, además de tratar otros requisitos de orden burocrático y administrativo (por ejemplo, cómo deben hacerse las comunicaciones, los formularios a llenar, las notificaciones y el pago de tasas, entre otros). También hay disposiciones relativas a los órganos derivados del tratado - por ejemplo, la asamblea. A fecha de 25 de marzo de 2019, 41 Estados eran parte de este tratado, entre los cuales están Estados Unidos, Japón, varios países de la Unión Europea, y algunos países periféricos como Armenia y Nigeria. Dicho tratado pretende «racionalizar y armonizar los requisitos formales establecidos por las oficinas nacionales o regionales de patentes para la presentación de solicitudes de patentes nacionales o regionales, así como el mantenimiento de las patentes» ("Tratado sobre el Derecho de Patentes», OMPI). En cuanto al reglamento, cabe mencionar que es un reglamento de desarrollo del tratado, por lo que continúan detallándose disposiciones de tipo administrativo.

Finalmente, con relación al Acuerdo ADPIC (Anexo 1C del Acuerdo de Marrakech por el que se establece la Organización Mundial del Comercio), que como advertimos resulta estratégico por la introducción de la propiedad intelectual en el sistema de comercio multilateral y, en especial, tras el tratado de cooperación entre la OMPI y la OMC, es imprescindible destacar ciertos lineamientos regulatorios vinculados con las patentes. Al respecto, el artículo 28 resulta crucial por cuanto determina los derechos exclusivos conferidos a los titulares de las patentes. Establece, en este sentido, que cuando la materia de la patente sea un producto, se podrá impedir que terceros lo fabriquen, usen u oferten para la venta, o lo importen para esos fines. En el caso de que la materia de la patente sea un procedimiento, tendrá el mismo derecho frente a terceros, pudiendo incluso impedir su utilización, incluso los titulares de la patente tendrán también el derecho de cesión o transferencia.

El artículo de referencia es, por consiguiente, la base de la figura jurídica de la patente como derecho frente a terceros. Tal como se revisará más adelante, el derecho reconocido en este artículo — relacionado con la figura de la propiedad 
privada - junto con lo establecido en el artículo $33^{12}$ (duración de la protección), constituyen el basamento para que el capital monopolista pueda monopolizar el usufructo sobre una innovación, sea para que se utilice o se restrinja, controlando o regulando con los mercados y los precios de los productos o procedimientos amparados por la patente. Precisamente es este derecho el que garantiza al capital monopolista su predominio en el capitalismo contemporáneo. A contrario sensu, el artículo 31 resulta interesante porque permite la utilización de la patente sin autorización del titular, en determinadas circunstancias y cumpliendo específicos requisitos; no obstante, dichos usos son muy limitados (por ejemplo, en situación de emergencia nacional).

La Parte III (artículos 41 y siguientes) obliga a los Estados miembro a cumplir con una serie de observancias, lo que armoniza, en estos extremos, las legislaciones de esos estados, y donde están incluidos los procedimientos administrativos y judiciales para dirimir los conflictos sobre propiedad intelectual. El artículo 41-1 obliga a los Estados miembro a que «establezcan procedimientos de observancia de los derechos de propiedad intelectual (...) que permitan la adopción de medidas eficaces contra cualquier acción infractora». Además, el apartado segundo del mismo artículo establece que los procedimientos que tengan que ver con la protección de estos derechos, deberán ser «justos y equitativos. No serán innecesariamente complicados o gravosos, ni comportarán plazos injustificables o retrasos innecesarios». Para Foladori (2014) estos litigios suponen grandes cantidades de dinero, a la vez que muestran, de nuevo, el carácter mercantilista de la figura de la patente. Por su parte, el artículo 50-3 posibilita a las autoridades judiciales exigir al demandante la aportación de una fianza.

Hemos analizado algunos aspectos de cuatro de los principales convenios internacionales relacionados con la propiedad industrial y las patentes. Es imprescindible observar que cada uno de ellos se inscribe en una ruta que conduce hacia una progresiva apropiación privada del general intellect: el Convenio de París fue el primero en regular internacionalmente la materia, el Tratado sobre Cooperación en materia de Patentes crea un sistema internacional de solicitud de patentes, el Convenio sobre el Derecho de Patentes promueve la armonización de los requisitos burocráticos y el Acuerdo sobre los ADPIC impulsa la inclusión

${ }^{12}$ Artículo 33: «Duración de la protección: la protección conferida por una patente no expirará antes de que haya transcurrido un periodo de 20 años contados desde la fecha de la presentación de la solicitud». Es importante señalar que la presentación de la solicitud ya permite bloquear nuevas solicitudes sobre una misma invención frente a terceros posibles solicitantes. 
de la propiedad intelectual en el sistema de comercio multilateral; de manera complementaria, establece una serie de mínimos obligatorios que todos los Estados pertenecientes a la OMC deben observar en sus legislaciones nacionales. A través de esa ruta, se establece el marco jurídico institucional que hace posible la reestructuración de los sistemas de innovación referida en el apartado anterior.

\section{La nueva migración calificada}

La migración calificada no puede ser comprendida al margen del contexto histórico en el que se despliega. Pretender explicarla a partir de «teorías» que hacen tabla rasa de dicho contexto, como el brain drain, brain gain, brain waste y brain abuse, y el hoy en boga brain circulation, es una empresa que no sólo carece de rigor analítico, sino que resulta incapaz de describir de modo adecuado el fenómeno en su dinámica e implicaciones más profundas. A partir de la década de 1990 - cuando se suscribe el Acuerdo ADPIC y se acelera el ritmo de patentamiento derivado de la reestructuración neoliberal de los sistemas de innovación - se produce un cambio significativo en la dinámica de la migración calificada: su ritmo crece a prácticamente el doble de la migración en general (véase cuadro 1).

\section{CUADRO 1}

Población emigrante con educación terciaria a escala global, 1990-2010

\begin{tabular}{lccc} 
& \multicolumn{2}{c}{ Año } & $\begin{array}{c}\text { Tasa anual de } \\
\text { crecimiento 1990-2010 }\end{array}$ \\
\hline Migrantes totales* & 1990 & 2010 & 1.8 \\
$\begin{array}{l}\text { Migrantes con educación terciaria** } \\
\text { Porcentaje de migrantes con }\end{array}$ & 1624503984 & 220729300 & 2.7781759 \\
educación terciaria & 10.5 & 12.6 & \\
\hline
\end{tabular}

Nota: *Datos provenientes de la UN DESA, 2013. ** La cifra de 1990 es para la población de 25 años y más y proviene de Artuc et al., 2014. La cifra de 2010 es para la población de 15 años y más, proviene de la base DIOC 2010/2011.

Fuente: estimaciones propias con base en los datos UN DESA, 2012 y 2013;

DIOC 2010/2011; Artuc et al., 2014. 
En este contexto, Estados Unidos, con Silicon Valley a la cabeza, se ubica en el epicentro de la reestructuración de los sistemas de innovación a escala global. De acuerdo con datos de la OMPI, Estados Unidos figura como el país que concentra el mayor número de patentes vigentes del mundo, con un total de 2 millones 934 mil 825 en 2017.13 El ritmo de patentamiento en ese país ha sido de tal magnitud que en los últimos 20 años se registraron más patentes que en 200 años de historia previa (Smith, 2012). Todavía más: el dominio estratégico ejercido por Estados Unidos en el ámbito de la innovación mundial y que confiere a Silicon Valley el carácter de Sistema Imperial de Innovación (Delgado, 2017), se manifiesta, además de por el volumen y ritmo de patentes generadas, por lo siguiente:

a) 7 de las primeras 10 y 36 de 100 principales empresas innovadoras del mundo tienen su matriz en Estados Unidos (Thomson Reuters, 2018).

b) 46 de las 100 universidades más innovadoras del mundo se ubican en territorio estadounidense (Ewalt, 2018).

c) 7 de las 10 startups más exitosas del planeta se ubican en Estados Unidos (Murgich, 2015).

Adicionalmente, conforme a la lógica extractiva de talento externo consustancial al Sistema de Innovación que impera actualmente en Estados Unidos, la tasa de patentamiento de extranjeros en ese país se elevó de 18 por ciento en 1963 a 52 por ciento en 2015 (U.S. Patent and Trademark Office, 2019). Dicho incremento se ha visto favorecido por el papel que en el ámbito de las políticas públicas ha ejercido el gobierno de Estados Unidos para mantener y profundizar su liderazgo científico y tecnológico en todo el orbe. En ese sentido, aparte del impresionante respaldo en materia de inversión pública en ciencia básica y aplicada (de 2.74 por ciento del PIB en 2016) (The World Bank, s/f), el gobierno estadounidense se distingue — sobre todo a partir de la década de 1990 — por desplegar una agresiva política de atracción de talento externo impulsada por la National Science Foundation y por su vigoroso impulso a una política migratoria altamente selectiva. No es casual, entonces, que la migración calificada y altamente calificada dirigida a Estados Unidos haya crecido a una tasa que duplica la correspondiente a la migración de menor calificación según se aprecia en la figura 2.

${ }^{13}$ Cabe aclarar, sin embargo, que de 2010 a 2017 China ha incrementado significativamente sus solicitudes de patentes, a grado tal que actualmente ocupa el segundo lugar con 2 millones 85 mil 367 patentes vigentes. 
FIGURA 2

Tasa de crecimiento anual (por cien) de la población de 22 años y más de edad inmigrante y nativa en Estados Unidos por nivel de escolaridad, 1990-2017

- Inmigrante Nativa

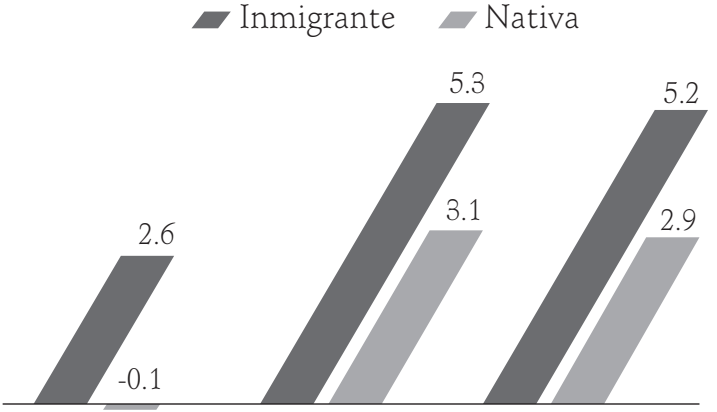

Menos de licenciatura

Licenciatura* Posgrado

* Incluye grado asociado a licenciatura

Fuente: SIMDE-UAZ. Estimación con base en U.S. Census Bureau, Samples Census 1990 y American Community Survey (ACS), 2017.

\section{2}

La participación de fuerza de trabajo calificada y altamente calificada proveniente del extranjero suple y complementa, como se desprende de la gráfica anterior, el ritmo relativamente más pausado con el que crece la masa crítica de científicos y tecnólogos nacidos en Estados Unidos. Otro dato significativo, tal como se percibe en la figura 3 , es que el segmento de inmigrantes calificados más dinámico es aquel que cuenta con el más alto nivel de calificación.

Sobresale también que la migración altamente calificada dirigida a Estados Unidos proviene principalmente de países periféricos o emergentes (véase figura 4). En realidad ocho de los principales países que aportan inmigrantes posgraduados a la primera potencia capitalista del mundo provienen de esos países. Este incremento se produce, como cabría esperarlo, en particular con inmigrantes formados en áreas directamente relacionadas con la innovación: CTIM (véase figura 5). 


\section{FIGURA 3}

Tasa de crecimiento anual de la población inmigrante calificada en Estados Unidos (por cien) 2000-2017

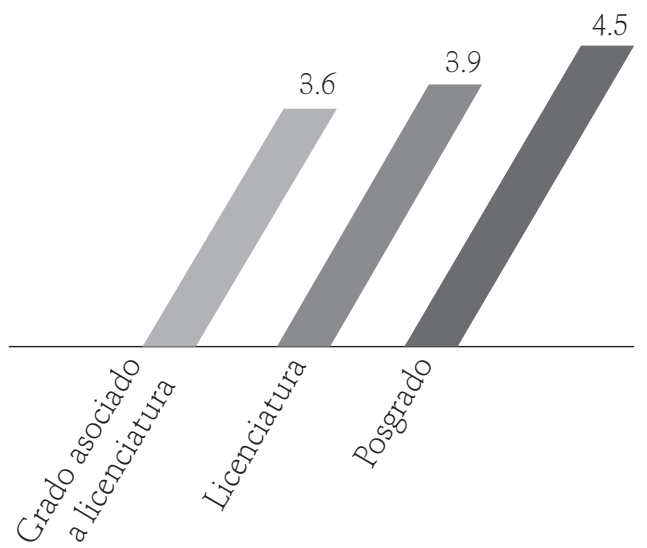

Fuente: SIMDE-UAZ. Estimación con base en U.S. Census Bureau, American Community Survey (ACS), varios años.

FIGURA 4

63

Tasa de crecimiento anual 1990-2017 (por cien) de inmigrantes con estudios de posgrado residentes en Estados Unidos

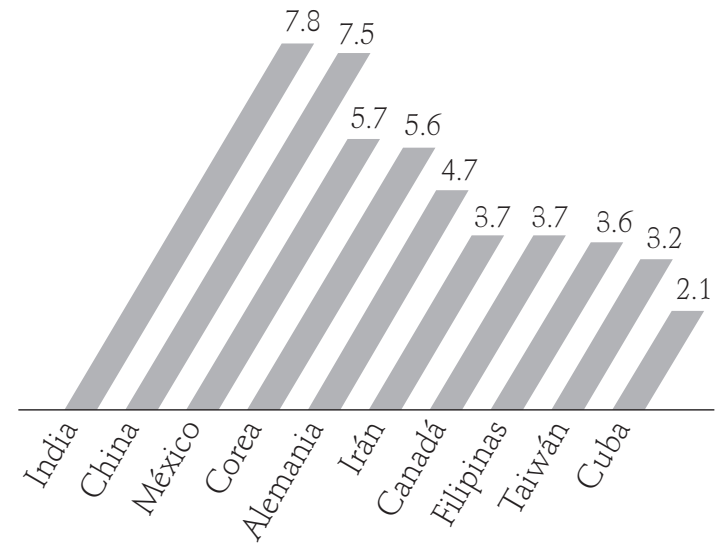

Fuente: SIMDE-UAZ. Estimación con base en U.S. Census Bureau, Samples Census 1990 y American Community Survey (ACS), 2017. 


\section{FIGURA 5}

Porcentaje de posgraduados en áreas CTIM residentes en Estados Unidos. Principales países de origen, 2017

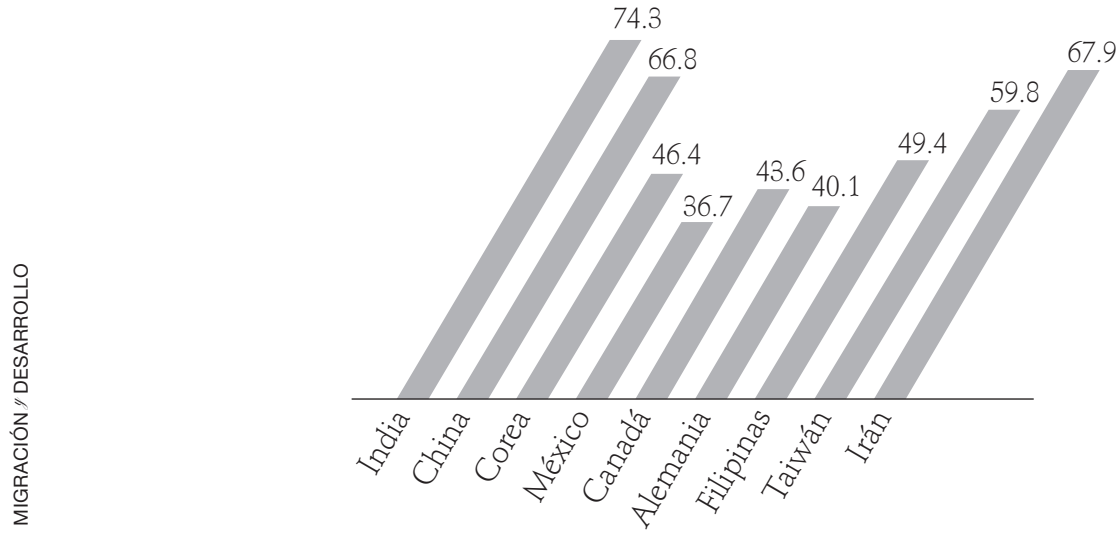

Fuente: SIMDE-UAZ. Estimación con base en U.S. Census Bureau y American Community Survey (ACS), 2017.

Es necesario agregar que hay una fuerte correlación entre los inmigrantes formados en áreas CTIM y el campo laboral en el que se desempeñan, en concreto dentro de ámbitos profesionales (89.6 por ciento) y en áreas asociadas con actividades de innovación (50.5 por ciento). Otro dato sobresaliente, es que el grado más alto obtenido por los inmigrantes fundadores de empresas en ingeniería y tecnología (startups) en Estados Unidos sea, precisamente, en áreas CTIM, con 75 por ciento (Wadhwa et al., 2007).

Es evidente, por tanto, que la reestructuración de los sistemas de innovación comandada por Estados Unidos - y sustentada en el nuevo marco regulatorio jurídico-institucional impulsado por la OMPI en mancuerna con la OMC- ha generado una nueva migración calificada proveniente de países periféricos o emergentes, misma que está creciendo a un ritmo mayor que la migración en general y que se nutre por científicos y tecnólogos formados en áreas CTIM.

\section{Reflexiones finales}

La reestructuración de los sistemas de innovación provee de un mirador privilegiado para analizar y comprender el significado y las implicaciones de las 
formas de apropiación del conocimiento, las cuales distinguen a la globalización neoliberal y subyacen a la lógica de dominación que acompaña a los acuerdos de libre comercio, promovidos por las grandes corporaciones multinacionales, y a las principales potencias imperialistas lideradas por Estados Unidos. No abarca como se ha venido estudiando, tratados en materia de comercio, innovación y migración calificada que benefician a todas las partes involucradas, sino de estrategias comandadas por el capital monopolista y los Estados imperiales que profundizan las dinámicas del desarrollo desigual a grados superlativos. No debe perderse de vista que nos encontramos ante una profunda crisis multidimensional del capitalismo contemporáneo que algunos autores catalogan como civilizatoria o terminal (Márquez, 2010; Foster, 2013; Arizmendi, 2016).

En esta crisis se encierra una carrera desenfrenada hacia la expansión y apropiación de los productos del trabajo científico-tecnológico, por ejemplo del general intellect, por parte del capital monopolista que, en su insaciable afán de lucro, torna el carácter progresista que Marx atribuía al desarrollo de las fuerzas productivas bajo el capitalismo, en su contrario: una ruta regresiva de progreso que atenta contra la naturaleza y contra la vida misma. Precisamente ese es el sentido que el capital confiere a la modernidad; sin embargo, como lo advierte Bolívar Echeverría,

la historia contemporánea, configurada en torno al destino de la modernización capitalista, parece encontrarse ante el dilema propio de una «situación límite»: o persiste en la dirección marcada por esta modernización y deja de ser un modo (aunque sea contradictorio) de afirmación de la vida, para convertirse en la simple aceptación selectiva de la muerte, o la abandona y, al dejar sin su soporte tradicional a la civilización alcanzada, lleva en cambio a la vida social en dirección a la barbarie. Desencantada de su inspiración en el «socialismo» progresista — que se puso a prueba no sólo en la figura del despotismo estatal del «mundo (imperio) socialista» sino también bajo la forma de un correctivo social a las instituciones liberales del «mundo (imperio) occidental»-, esta historia parece haber llegado a clausurar aquello que se abrió justamente con ella: la utopía terrenal como propuesta de un mundo humano radicalmente mejor que el establecido, y realmente posible (2011:70).

Pese a ello, como el propio autor también lo plantea, es posible

detectar en el campo de la teoría la posibilidad de una modernidad diferente de la que se ha impuesto hasta ahora, de una modernidad no capitalista (...) (la cual) no 
sería «un proyecto inacabado»; sería, más bien, un conjunto de posibilidades exploradas y actualizadas sólo desde una perspectiva y en un solo sentido, y dispuesto a lo que aborden desde otro lado y lo iluminen con una luz diferente (Echeverría, 2011:70).

Esto último no es ajeno del todo a las posibilidades que encierra la profunda crisis por la que atraviesa el capitalismo contemporáneo. Nuestro análisis devela que el marco jurídico-institucional en el que se sustenta la reestructuración de los sistemas de innovación en la actualidad no representa en absoluto una barrera infranqueable. La creciente dependencia de los países imperialistas liderados por Estados Unidos de científicos y tecnólogos provenientes de países periféricos o emergentes en la generación de patentes no devela únicamente las debilidades que encierra esa barrera, sino que en un sentido más profundo, cuestiona la esencia misma de la relación centro-periferia.

\section{Referencias}

Amin, Samir (2013), The implosion of capitalism, London, Pluto Press.

(2015), "Contemporary Imperialism», Monthly Review, 67(3), pp. 23-36.

Arizmendi, Luis (2016), El Capital ante la crisis epocal del capitalismo, Ciudad de México, Instituto Politécnico Nacional.

Artuc, Erhan, Frederic Docquier, Caglar Ozden, Christopher Parsons (2014), «A global assessment of human capital mobility: the role of non-OECD destinations», Policy Research Working Paper (6863), en http://documents.worldbank.org/curated/ en/759721468339651317/A-global-assessment-of-human-capital-mobility-the-role -of-non-OECD-destinations

Castillo, Lázaro, Jesús Lavín y Norma Angélica Pedraza (2014), «La gestión de la triple hélice: fortaleciendo las relaciones entre la universidad, empresa y gobierno», Multiciencias, 14(4), pp. 438-446.

Delgado Wise, Raúl (2015), "Unravelling Highly Skilled Migration from Mexico in the Context of Neoliberal Globalization», en Stephen Castles, Derya Ozkul y Magdalena Arias (eds.), Social transformation and migration. National and local experiences in South Korea, Turkey, Mexico and Australia, Londres, Palgrave Macmillan, pp. 201-217. (2017), «El capital en la era de los monopolios generalizados: apuntes sobre el capital monopolista», Observatorio del Desarrollo. Investigación, reflexión y análisis, 6(18), pp. 48-58. 
Delgado Wise, Raúl y Mónica Chávez (2016), «iPatentad, patentad!: apuntes sobre la apropiación del trabajo científico por las grandes corporaciones multinacionales», Observatorio del Desarrollo. Investigación, reflexión y análisis, 5(15), pp. 1-12.

Echeverría, Bolívar (2011), Crítica de la modernidad capitalista, La Paz, OXFAM.

Echeverría, Javier (2003), La revolución tecnocientífica, Madrid, Fondo de Cultura Económica.

Edquist, Charles (1997), «Systems of innovation approaches. Their emergence and characteristics», en Charles Edquist (ed.), Systems of Innovation: Technologies, Institutions and Organizations, Londres, Pinter/Cassell, pp. 1-35.

(2001), Systems of innovation for development. Background paper for Chapter 1: «Competitiveness, Innovation and Learning: Analytical Framework». UNIDO World Industrial Development Report (WIDR).

Ewalt, David M. (2018), «Reuters top 100: the World's most innovative universities, 2018», en https://www.reuters.com/article/us-amers-reuters-ranking-innovativeuniv/reuters-top-100-the-worlds-most-innovative-universities-2018-idUSKCN1MLOAZ

Foladori, Guillermo (2014), "Ciencia ficticia», Estudios Críticos del Desarrollo, 4(7), pp. 41-66.

Foster, John B. (2013), "The epochal crisis», Monthly Review, 65(5), pp. 1-12.

Graffagnini, Mark J. (2009), "Corporate strategies for nanotech companies and investors in new economic times», Nanotechnology Law \& Business, 6(2), pp. 251-276.

Harvy, David (2004), «El «nuevos imperialismo: acumulación por desposesión», Socialist Register, 40, pp. 99-129.

Hernández, Aleida (2014), «La producción jurídica de la globalización en el marco de un pluralismo jurídico transnacional», Umbral. Revista de Derecho Constitucional (4), pp. 131-159.

López, Liliana (2014), «El pluralismo jurídico: una propuesta paradigmática para repensar el Derecho», Umbral. Revista de Derecho Constitucional (4), pp. 31-64.

McKinsey Global Institute (2015), "Playing to win: the new global competition for corporate profits", en https://www.mckinsey.com/ /media/B71EDD78D1364375 9492C8D69FA38CCF.ashx

Márquez, Humberto (2010), "La gran crisis del capitalismo neoliberal», Andamios (13), pp. $57-84$.

Míguez, Pablo (2013), «Del General Intellect a la tesis del «capitalismo cognitivo»: aportes para el estudio del capitalismo del siglo XXI», Bajo el Volcán, 13(21), pp. 27-57.

Murgich, Valeria (2015), "Las startup más exitosas (y famosas) del mundo», Merca2.0, en https://www.merca20.com/las-startup-mas-exitosas-y-famosas-del-mundo/ 
Niosi, Jorge, Paolo Saviotti, Bertrand Bellon y Michael Crow (1993), «National systems of innovation: in search of a workable concept», Technology in Society, 15(2), pp. 207-227.

Organización Mundial de la Propiedad Intelectual (OMPI) (s/f), «خ் Qué es la propiedad intelectual?», en https://www.wipo.int/about-ip/es/ (s/f), «Patentes», en http://www.wipo.int/patents/es/ (s/f), «Tratado sobre el Derecho de Patentes», en https://www.wipo.int/ patent-law/es/plt.htm (2017), «Cómo proteger sus invenciones en otros países: Preguntas frecuentes sobre el Tratado de Cooperación en materia de Patentes (PCT)», en https:// www.wipo.int/pct/es/faqs/faqs.html

Ramírez, René (2017), La gran transición en busca de nuevos sentidos comunes, Quito, Centro Internacional de Estudios Superiores de Comunicación para América Latina.

Rodríguez Spinelli, Francesca (2008), «El sistema de patentes y el desarrollo tecnológico: algunas consideraciones en el marco de la libre competencia», Propiedad Intelectual, 7(11), pp. 87-109.

Schmitz Vaccaro, Christian (2013), «Evolución de la regulación internacional de la propiedad intelectual», Revista La Propiedad Inmaterial, (17), pp. 63-92.

Smith, Gina (2012), "Can the U.S. patent system be saved?», Computer World, en http:// www.computerworld.com/article/2505817/it-management/can-the-u-s-patentsystem-be-saved-htm

The World Bank (s/f), "Research and development expenditure», en https:/data. worldbank.org/indicator/gb.xpd.rsdv.gd.zs

Thomson Reuters (2018), «The top 100 global technology leaders», en https://www. thomsonreuters.com/content/dam/ewp-m/documents/thomsonreuters/en/pdf/ reports/thomson-reuters-top-100-global-tech-leaders-report.pdf

U.S. Patent and Trademark Office (2019), «U.S. patent statistics chart calendar. Years 1963-2015", en https://www.uspto.gov/web/offices/ac/ido/oeip/taf/us_stat.htm

UN DESA (2012-2013), «Tables of total migrant stock at mid-year by origin and by major area, region, country or area of destination", en http://www.un.org/en/development/ desa/population/migration/data/estimates2/estimatesage.shtml

Vargas, Juancarlos E. (2012), «El derecho internacional económico y la gobernabilidad de las organizaciones económicas internacionales: un análisis jurídico-político», Revista Boliviana de Derecho (13), pp. 116-135.

Vidaurreta, Guillermo Esteban (2013), «Los fundamentos del derecho de patentes», Serie Breviario en Relaciones Internacionales (28), pp. 1-14. 
Wadhwa, Vivek, Ben Rising, AnnaLee Saxenian y Gary Gereffi (2007), Education, entrepreneurship and immigration: America's new immigrant entrepreneurs, part II (Master of Engineering Management Program), Duke University, School of Information, U.C. Berkeley, Kauffman Foundation, en https://www.kauffman.org/ /media/ kauffman_org/research\%20reports\%20and\%20covers/2007/06/entrep_immigrants _261207.pdf

Záyago, Édgar (2013), "The social relevance of nanotechnology in Mexico», Sociología y Tecnociencia, 2(3), pp. 48-70.

\section{Textos normativos}

Convenio de París para la Protección de la Propiedad Industrial, del 20 de marzo de 1883, en https://wipolex.wipo.int/es/text/287557

Tratado de Cooperación en materia de Patentes, elaborado el 19 de junio de 1970, en https://wipolex.wipo.int/es/text/288639

Reglamento del Tratado de Cooperación en materia de Patentes, en vigor el 1 de julio de 2018, en https://wipolex.wipo.int/es/text/494067

Tratado sobre el Derecho de Patentes, adoptado el 1 de junio de 2000, en https://wipolex. wipo.int/es/text/288774

Reglamento del Tratado sobre el Derecho de Patentes, en vigor el 1 de enero de 2006, en https://wipolex.wipo.int/es/text/289474

Anexo 1C del Acuerdo de Marrakech: Acuerdo sobre los Aspectos de los Derechos de Propiedad Intelectual relacionados con el Comercio, en vigor el 1 de enero de 1995, en https://www.wto.org/spanish/docs_s/legal_s/27-trips.pdf 